\title{
Patterns and Presentation of Prostate Cancer in the Brong Ahafo Region of Ghana: A 6-Year Single Center Retrospective Study
}

\author{
Alexander Kofi Egote1 ${ }^{*}$, Paul Poku Sampene Ossei², Eric Agyeman-Duah², John Taylor2 (D), \\ Evans Quarshie ${ }^{1}$
}

${ }^{1}$ Department of Surgery (Urology Unit), Brong Ahafo Regional Hospital, Sunyani, Ghana

${ }^{2}$ Department of Pathology, School of Medical Sciences, KNUST/Komfo Anokye Teaching Hospital, Kumasi, Ghana

Email: *alexanderegote@yahoo.com

How to cite this paper: Egote, A.K., Ossei, P.P.S., Agyeman-Duah, E., Taylor, J. and Quarshie, E. (2019) Patterns and Presentation of Prostate Cancer in the Brong Ahafo Region of Ghana: A 6-Year Single Center Retrospective Study. Health, 11, 351-360. https://doi.org/10.4236/health.2019.114031

Received: December 14, 2018

Accepted: April 9, 2019

Published: April 12, 2019

Copyright $\odot 2019$ by author(s) and Scientific Research Publishing Inc. This work is licensed under the Creative Commons Attribution International License (CC BY 4.0).

http://creativecommons.org/licenses/by/4.0/

\section{Abstract}

Introduction: Prostate cancer is gradually reaching a very high incidence in Africa, especially in the Sub-saharan region. Understanding the dynamics in occurrence of the disorder is one approach to developing effective public health programmes and interventions that will help curb the rising incidence. Objective: This study was aimed at reducing the paucity of data on prostate cancer by assessing the incidence, patterns and presentation in the Brong Ahafo Region of Ghana. We sought to provide region-specific hardcore data that will help to assess the issue and provide remedies. Method and Materials: All prostate disease cases recorded from the year 2009 to 2014 were retrospectively reviewed. Subjects from 40 years (based on previous studies) and above were eligible for screening. Diagnostic and screening tools for prostate cancer at the study site were family history, serum prostate specific antigen (PSA) test, digital rectal examination, urological ultrasound scan and histopathology (biopsy). Age, PSA values and year of screening/diagnosis were also retrieved from patient folders/archives for the purposes of the study. Histological findings and parameters considered in the study included diagnosis, carcinoma grading, perineural invasion (PNI) and percentage of affected tissues (\%TA). Results: Prostate cancer constituted 236 cases (40.07\%) of the 589 prostate diseases reviewed. The highest annual prevalence was recorded in 2014 with an incidence rate of $21.6 \%$ (51 cases). The ages of patients ranged from 46 to 101 years with a modal age range of $70-79$ years and a mean \pm SD of $71.7 \pm 11.2$. The mean PSA value recorded was 37.5 $\mathrm{ng} / \mathrm{ml}( \pm 68.9)$ with predominance in the $11-20.9 \mathrm{ng} / \mathrm{ml}$ (61 cases/patients) (27.9\%) range. Moderately differentiated adenocarcinoma was the dominant grade of prostate cancer accounting for $61.4 \%$ (145 cases) of the 236 cases. 
There was a significant correlation $(\mathrm{p}=0.001)$ between grading of prostate cancer and perineural invasion. Only $21.2 \%$ graded cancer cases had perineural invasion with $>50 \%$ affected tissues found in half of them. Conclusion: There is a high incidence (40.07\%) of prostate cancer in the Brong Ahafo Region of Ghana, presenting mostly with advanced prostatic carcinoma. Reported cases also show high \%TA and PNI. Development and implementation of public health interventions are needed to address some of these issues.

\section{Keywords}

Prevalence, Prostate Cancer, Serum PSA, Brong Ahafo Region, Ghana

\section{Introduction}

Prostate cancer is gradually reaching a very high incidence in Africa, especially in the Sub-Saharan region [1] [2]. The absence of proper knowledge on prostate cancer and improper lifestyle has contributed immensely to the increase in the incident rate in Ghana [3] [4]. Studies have documented countries such as Nigeria and South Africa as among the few countries with reliable and accurate statistical information on the prevalence of prostate cancer [5]. Very little is known of the current trends and incidence in Ghana and hence makes it difficult to have accurate data on prevalence and mortality rate of prostate among Ghanaian men [1] [6]. Efforts by some researchers to provide this information cannot be overlooked as they document the prevalence of prostate cancer in some parts of the country [3] [7] [8]. Results from these studies indicate that cancer cases are rising steadily and among them, cancer of the prostate was increasing exponentially. Region specific data is one way of providing reliable information that helps to tailor a particular public health need. By examining and analysing data from our region, we hope that we can provide enough evidence to support health decisions in relation to prostate cancer in the region.

\section{Methodology}

All prostate diseases recorded at the Urology Unit of the Surgical Department, Brong Ahafo Regional Hospital, Sunyani-Ghana from 2009 to 2014 were retrospectively reviewed. The Brong Ahafo Regional Hospital is one of the major hospitals in Ghana serving the region. The hospital has many infrastructures and serves as a referral centre. The geographical location of the hospital, the road network of the Country and the commercial and metropolitan nature of the region make the hospital accessible to all the areas that share boundaries with the region and others that are farther away. Subjects from 40 years and above (based on previous studies [4]) were eligible for screening. Diagnostic and screening tools for prostate cancer at our facility at the time of study were family history, serum prostate specific antigen (PSA) test, digital rectal examination, Urological ultrasound scan and histopathology (ultrasound guided biopsy) with 12 to 16 cores. 
Age, PSA values and year of screening/diagnosis were retrieved from patient folders/archives for purposes of the study. Histological findings considered included the diagnosis, carcinoma grading, perineural invasion and percentage of affected tissues. The carcinomas were graded into well, moderate and poorly differentiated based on Gleason score "2 - 4", " 5 - 7" and " 8 - 10" respectively [9] at the time of the study. Men below 40 years were not eligible this study and only confirmed prostate cancer cases were considered in this study.

\section{Data Analysis}

Data analysis was done using simple descriptive tests with the help of SPSS (Version 20.0; SPSS Inc., Chicago, IL). To account for the underlying sampling frame and to provide representative population prevalence estimates, the sample population was stratified by age, year, PSA, grading and the frequency of distribution was determined among the different strata. The prevalence for the various histological presentations was also examined.

\section{Results}

A total of 589 prostate diseases were reviewed during the period of study. Out of this, prostate cancer constituted 236 cases $(40.07 \%)$ and the highest annual prevalence was recorded in 2014 with incident rate of $21.6 \%$. This was followed by 2010, 2011, 2012 and 2013, in descending order of incidence with the least in 2009 (5.9\%). Out of the 236 cases, 7 cases had no patient age information and age distribution showed a minimum and maximum of 46 and 101 years respectively. The modal age range was $70-79$ years and the least incidence was recorded among the age range $40-49$, and $\geq 100$ years (Table 1 ).

The mean PSA value recorded in our study was $37.5 \mathrm{ng} / \mathrm{ml}( \pm 68.9)$ and it ranged from 0.4 to $838 \mathrm{ng} / \mathrm{ml}$. Test values fell within the range $11-20.9 \mathrm{ng} / \mathrm{ml}$ (27.9\%), followed by $4-10.9$ (22.5\%) and $41-50.9 \mathrm{ng} / \mathrm{ml}$ (14.6\%). Only 4 PSA values were below $4 \mathrm{ng} / \mathrm{ml}$ and 8 were above $100 \mathrm{ng} / \mathrm{ml}$ (Table 1). The Gleason score was used to histologically grade $98.3 \%$ of the 236 cases. Moderately differentiated adenocarcinoma was the dominant grade accounting for $61.4 \%$ (145 cases). Well differentiated and poorly differentiated adenocarcinoma accounted for $0.8 \%$ and $36.0 \%$ respectively. Four cases were not graded (Table 1 ) and there was a significant correlation $(\mathrm{p}=0.001)$ between grading of prostate cancer and perineural invasion. Out of the 232 graded adenocarcinomas, only 50 (21.2\%) had perineural invasion and most of the biopsies examined in our facility had more than $70 \%$ tissues affected with carcinoma. These were primarily associated with advanced form of prostate cancer. Overall, about 37 biopsies had $50 \%$ affected tissues whiles 10 had less than $10 \%$ tissues affected (Table 2).

\section{Discussion}

There is a high incidence rate of prostate cancer among black men, especially those in the sub-Saharan region. It is therefore not surprising that $40.07 \%$ of total 
prostate diseases documented at study site was prostate cancer. This is slightly above the 39.0\% incidence rate recorded in Kumasi by Gyamfi et al., [9] in 2014. Similar findings to our study were recorded in South Africa and Senegal with prevalence rate of $43 \%$ and $30.6 \%$ respectively [2]. Studies in Tobago and Nigeria documented a contrasting prevalence rate of $10.0 \%$ and $15.7 \%$ respectively [1].

Table 1. Frequency distribution of year, age, PSA values and grading of prostate cancer.

\begin{tabular}{|c|c|c|c|c|}
\hline & Frequency & Percentage (\%) & Total $(n=236)$ & Mean (SD) \\
\hline \multicolumn{5}{|l|}{ YEAR } \\
\hline 2009 & 14 & 5.9 & \multirow{6}{*}{236} & \\
\hline 2010 & 48 & 20.3 & & \\
\hline 2011 & 47 & 19.9 & & \\
\hline 2012 & 45 & 19.1 & & \\
\hline 2013 & 31 & 13.1 & & \\
\hline 2014 & 51 & 21.6 & & \\
\hline \multicolumn{5}{|l|}{ AGE } \\
\hline $40-49$ & 2 & 0.8 & \multirow{7}{*}{229} & \multirow{7}{*}{$72.01(10.2)$} \\
\hline $50-59$ & 24 & 10.2 & & \\
\hline $60-69$ & 64 & 27.1 & & \\
\hline $70-79$ & 83 & 35.2 & & \\
\hline $80-89$ & 44 & 18.6 & & \\
\hline $90-99$ & 11 & 4.7 & & \\
\hline 100 and above & 2 & 0.8 & & \\
\hline \multicolumn{5}{|l|}{ PSA } \\
\hline$<4$ & 4 & 1.8 & \multirow{12}{*}{218} & \multirow{12}{*}{$37.5(68.9)$} \\
\hline $4-10.9$ & 49 & 22.5 & & \\
\hline $11-20.9$ & 61 & 27.9 & & \\
\hline $21-30.9$ & 21 & 9.6 & & \\
\hline $31-40.9$ & 17 & 7.8 & & \\
\hline $41-50.9$ & 32 & 14.6 & & \\
\hline $51-60.9$ & 7 & 3.2 & & \\
\hline $61-70.9$ & 3 & 1.9 & & \\
\hline $71-80.9$ & 2 & 0.9 & & \\
\hline $81-90.9$ & 1 & 0.5 & & \\
\hline $91-100.9$ & 13 & 5.9 & & \\
\hline$>100.9$ & 8 & 3.7 & & \\
\hline \multicolumn{5}{|l|}{ GRADING } \\
\hline WD & 2 & 0.8 & \multirow{4}{*}{236} & \multirow{4}{*}{$7.22( \pm 0.91)$} \\
\hline $\mathrm{MD}$ & 145 & 61.4 & & \\
\hline $\mathrm{PD}$ & 85 & 36.0 & & \\
\hline Ungraded & 4 & 1.7 & & \\
\hline
\end{tabular}

SD = Standard Deviation; PSA = Prostate Specific Antigen Values; WD = Well Differentiated; MD = Moderately Differentiated; PD = Poorly Differentiated. 
Table 2. Grading of adenocarcinoma with perineural invasion, tissue affected and serum PSA.

\begin{tabular}{|c|c|c|c|c|c|}
\hline & \multicolumn{3}{|c|}{ GRADING } & \multirow{2}{*}{ Total } & \multirow{2}{*}{ p-value } \\
\hline & WD & $\mathrm{MD}$ & PD & & \\
\hline \multicolumn{6}{|l|}{ PNI } \\
\hline $\mathrm{N}$ & \multirow{2}{*}{2} & 92 & 48 & 142 & \multirow[t]{2}{*}{0.001} \\
\hline $\mathrm{P}$ & & 27 & 23 & 50 & \\
\hline \multicolumn{6}{|l|}{$\% \mathrm{TA}$} \\
\hline$<10$ & & 9 & & 10 & \multirow{4}{*}{0.18} \\
\hline $10-39$ & 1 & 25 & 13 & 28 & \\
\hline $40-69$ & 1 & 43 & 18 & 62 & \\
\hline$>70$ & \multirow{14}{*}{2} & 41 & 42 & 83 & \\
\hline PSA & & 2 & 2 & 4 & \multirow{13}{*}{0.645} \\
\hline$<4$ & & 33 & 15 & 48 & \\
\hline $4-10.9$ & & 38 & 21 & 61 & \\
\hline $11-20.9$ & & 15 & 6 & 21 & \\
\hline $21-30.9$ & & 11 & 6 & 17 & \\
\hline $31-40.9$ & & 17 & 15 & 32 & \\
\hline $41-50.9$ & & 3 & 4 & 7 & \\
\hline $51-60.9$ & & 1 & 2 & 3 & \\
\hline $61-70.9$ & & 2 & 2 & 2 & \\
\hline $71-80.9$ & & 1 & & 1 & \\
\hline $81-90.9$ & & 6 & 5 & 11 & \\
\hline $91-100.9$ & & 5 & 3 & 8 & \\
\hline$>100.9$ & & 3 & 3 & 0 & \\
\hline
\end{tabular}

$\mathrm{TA}=\%$ Tissue affected; PNI = Perineural Invasion; N = Perineural Invasion Absent; P = Perineural Invasion Present.

The peak prevalence was recorded in the year 2014. The year 2010 recorded the second highest number of prostate cancer cases at the Regional hospital followed by 2011 and 2012 with the least prevalence in 2009 (Table 1). An important assertion of the annual distribution of prostate cancer is the increase in prevalence rate from 2009 to 2014 (Table 1). Approximately a $72.5 \%$ increase was observed within the 6 years of study. This can be attributed to different factors such as efficient public health programmes on prostate cancer ensuring that patients visit the health center regularly for screening and the accuracy in the diagnosis from our facility. The use of serum PSA has also increased the prevalence rate in most countries [10]. There has been a decrease in prevalence rate to 31.12\% in Asia [11] whiles the opposite has been recorded in the Arab world [12]. The rise in prevalence rate in our study shows that Ghanaian men are at a high risk and if measures are not put in place, they will continue to be at an increased risk.

Prostate cancer is generally prevalent among the elderly and often tagged as "disease of the elderly". Unlike whites, African men are at a higher risk as early 
as 40 years of age [4] [13]. Though the findings of our study affirm this assertion by recording a minimum and maximum age of 46 and 101 years respectively, It is very likely that a similar prevalent situation may be recorded among younger men ( $<40$ years old). The mean age in Iran was 66.2 years [14] whiles that of Nigeria, Kenya and Senegal recorded 68, 67 and 69 years respectively [2]. Togo and Burkina Faso also recorded a mean age of 70 and 71.5 years respectively [14] [15] and these are by far to the best of our knowledge, the closest to our study across the continent. It is very likely that the proximity of the two countries to Ghana may have accounted for this result. Considering the reviewed literature, It can be inferred that African men in their 60s and 70s are at a higher risk of developing the disease. Though African men are known to be predisposed at 40 years and above [4] [13] [16] [17], this study recorded a very low prevalence among those in their $40 \mathrm{~s}(0.8 \%)$. Prostate cancer at the early stages is asymptomatic until it reaches the advanced stages. This therefore may have contributed to the low prevalence recorded among men in their 40s. In any case, most of the cases presented to our facility are mostly at the aggressive stage of differentiation. Studies have confirmed high prostate cancer mortality rate in Africa, denoting least chance of survival especially when at the advanced stages [13]. Significant relationship between grading of tumour and age have been established and this has shown that tumours advance to more lethal forms at the very late stage of life and hence likely to cause death of the elderly compared to young adults [8] [9].

Serum PSA as a diagnostic tool has received a lot of criticism ever since it was adopted in diagnosing prostate cancer. It has been suggested that serum PSA churns out $70 \%$ false positives, making it an unreliable tool for diagnosing prostate cancer [18]. According to Glady et al., [10], serum PSA has limitations which questioned its efficacy. In their assertion, they postulated that serum PSA does not reliably predict tumour grade of stage of metastasis. It is also not regarded as a prostate cancer specific antigen but solely reflects tumour volume. Hence several conditions such as prostatitis and benign prostate hyperplasia can affect serum PSA which will in turn churn out false positive or negative results. Yarney et al., [19] also asseverated that more lethal stage of tumour (poorly differentiated) are likely to produce lesser serum PSA. Our findings share similar sentiment with Glady et al., [10] as no statistical relationship was established between serum PSA and tumour grade (Table 2, p = 0.645). However, it agreed with the assertion that poorly differentiated adenocarcinoma produces less serum PSA than moderately differentiated adenocarcinomas (Table 2).

Approximately $1.8 \%$ (Table 2) serum PSA in our study were below the standard value of $4.0 \mathrm{ng} / \mathrm{ml}$. The dominant PSA range was from 4 to $20.9 \mathrm{ng} / \mathrm{ml}$ whiles $>20.9 \mathrm{ng} / \mathrm{ml}$ accounted for $48.1 \%$ (Table 2). Contrasting trend was documented in Accra by Yarney et al., [19] with $14.1 \%$ obtaining $<10 \mathrm{ng} / \mathrm{ml}$ and $12.2 \%$ obtaining between 10 and $20 \mathrm{ng} / \mathrm{ml}$. Saadat et al., [20] also reported $84.8 \%$ of patients obtaining serum PSA above $20 \mathrm{ng} / \mathrm{ml}$. The mean PSA value obtained in our study (37.5 ng/ml) (Table 2) was far below that of Shih et al., [21] (134.4 
$\mathrm{ng} / \mathrm{ml})$ and Saadat et al., [20] (233.3 $\mathrm{ng} / \mathrm{ml})$ but higher than other recorded values [14] [22].

Despite the backlash, serum PSA has been helpful in diagnosing asymptomatic prostate cancer [23] in other facilities and in our facility as well. It must therefore be used together with urological ultrasound scan and histology for accurate diagnosis.

Gleason score grading of tumours in this study was in line with most studies [14]. Most tumours were presented at late stage, predominantly moderately differentiated whiles early diagnosis was very few. Polar findings were reported by Yarney et al., [19] and Saadat et al., [20] showing predominant well and poorly differentiated adenocarcinoma respectively. We however present our findings with caution bearing in mind the new grading system that has been introduced. We present our results in the context of the time and the grading system that was available during the course of the study.

Perineural invasion is the infiltration of cancer cells in the endoneurium, perineurium or epineurium. This is commonly associated with advanced (metastatic) stage of tumours [20]. Statistical significant correlation was established between tumour grades and perineural invasion (Table $2, \mathrm{p}=0.001$ ). Only advanced tumour (especially moderately differentiated adenocarcinoma) were histologically proven to invade surrounding nerve cells. Fifty men had the surrounding nerve cells of the prostate invaded by cancer with 23 of them attributed to poorly differentiated form of prostate cancer (Table 2). Because most men were diagnosed at an advanced stage, most of them had over $50 \%$ of tissues affected. A greater proportion showed $70 \%$ affected tissues depicting the widespread of tumour and possible metastasis to other organs. However, there was no significant association (Table $2, \mathrm{p}=0.18$ ) between $\% \mathrm{TA}$ and tumour grades.

\section{Conclusion}

There is a high incidence rate of prostate cancer in the Brong Ahafo region. Ghanaian men between the ages of 60 to 79 years are mostly diagnosed with advanced prostatic carcinoma, most especially moderately differentiated. Reported cases showed high \%TA and PNI in our facility. Prostate cancer is asymptomatic at an early pathogenetic stage and therefore contributes to late diagnosis. Screening must be done for all men above 39 years to ascertain conditions of their prostate. This will curb late diagnosis and further metastasis of advancement of cancer into a more lethal state. Serum PSA must also be used as a diagnostic tool together with ultrasound scan and histology to ensure precise and accurate diagnosis and management of prostate cancer.

\section{Ethical Committee Approval}

Ethical approval was sought from the Committee on Human Research and Publication Ethics from our institution and was approved before the commencement of this project. 


\section{Limitations}

The study only presented results over a 6 year period from 2009 to 2014 and therefore current trends in the region are not known. However the study should be appreciated in its context of time and available resources at the facility.

\section{Authors Contribution}

EAK and PSO conceived the study, QE, ADE and JT compiled and analysed the data, EAK, PSO, ADE, QE and JT wrote the manuscript, EAK and PSO edited the manuscript. All authors read and approved the final manuscript.

\section{Source of Funding}

No funding was obtained for this study.

\section{Data Availability Statement}

Study data is available and will be provided by the authors upon request.

\section{Acknowledgements}

Wish to acknowledge staff of the Department of Surgery (Urology Unit) BrongAhafo Regional Hospital, Sunyani-Ghana and Department of Pathology, School of Medical Sciences-KNUST/KomfoAnokye Teaching Hospital Ghana for their numerous parts played toward the success of the study. An earlier version of the manuscript has been presented as conference abstract in Abstracts from the $37^{\text {th }}$ Congress of the Societe Internationaled'Urologie, centro de congressos de lisboa, October 19-22, 2017.

Available at: https://link.springer.com/article/10.1007\%2Fs00345-017-2090-9.

\section{Conflicts of Interest}

The authors declare no conflicts of interest regarding the publication of this paper.

\section{References}

[1] Odedina, F.T., Akinremi, T.O., Chinegwundoh, F., Roberts, R., Yu, D., Reams, R.R. et al. (2009) Prostate Cancer Disparities in Black Men of African Descent: A Comparative Literature Review of Prostate Cancer Burden among Black Men in the United States, Caribbean, United Kingdom, and West Africa. Infectious Agents and Cancer, 4, S2. https://doi.org/10.1186/1750-9378-4-S1-S2

[2] Jalloh, M., Niang, L., Ndoye, M., Labou, I. and Gueye, S.M. (2013) Prostate Cancer in Sub Saharan Africa. Journal of Nephrology and Urology Research, 1, 15-20. https://doi.org/10.12970/2310-984X.2013.01.01.4

[3] Obu, R. (2014) Review: Men's Health Foundation Ghana. International Research on Medical Sciences, 2, 39-46.

[4] Egote, A.K., Ossei, P.P.S., Agyemang-Duah, E., Quarshie, E. and Taylor, J.(2018) Age as a Risk Factor for Prostate Diseases: A 6-Year Selective Prospective Study among Males in the BrongAhafo Region of Ghana. Journal of Medical Research, 4, 
154-157.

[5] Adeloye, D., David, R.A., Aderemi, A.V., Iseolorunkanmi, A., Oyedokun, A., Iweala, E.E., et al. (2016) An Estimate of the Incidence of Prostate Cancer in Africa: A Systematic Review and Meta-Analysis. PLoS ONE, 11, e0153496.

https://doi.org/10.1371/journal.pone.0153496

[6] Egote, A.K., Ossei, P.P.S., Taylor, J. and Bortier, T. (2018) Enucleation of a Giant Prostatic Hyperplasia in Ghana: A Case Report and Mini Literature Review. Case Reports in Clinical Medicine, 7, 583-593. https://doi.org/10.4236/crcm.2018.712053

[7] Arthur, F.K.N., Yeboah, F.A., Adu-Frimpong, M., Sedudzi, E.E. and Boateng, K.A. (2005) Prostate Cancer Screening in Ghana: A Clinical Benefit? Journal of science and Technology, 25, 9-12.

[8] Laryea, D.O., Awuah, B., Amoako, Y.A., Osei-Bonsu, E., Dogbe, J. and Larsen-Reindorf, R. (2014) Cancer Incidence in Ghana, 2012: Evidence from a Population-Based Cancer Registry. BMC Cancer, 14, 362.

https://doi.org/10.1186/1471-2407-14-362

[9] Gyamfi, M.A., Osei, O.A. and Osabutey, C.K. (2014) Efficacy of Supportive Histomorphological Features in Prostate Cancer Diagnosis. Medical \& Surgical Urology, 3, 142 .

[10] Glady, A., Hamidah, E., Prasetyo, R.B. and Sutiono, A.B. (2016) Pattern of Prostate Specific Antigen and Gleason Score in Relation to Imunohistochemistry Features in Prostate Adenocarcinoma Patients in Dr. Hasan Sadikin General Hospital. International Journal of Integrated Health Sciences, 4, 1-7. https://doi.org/10.15850/ijihs.v4n1.679

[11] Suzuki, K. (2009) Epidemiology of Prostate Cancer and Benign Prostatic Hyperplasia. JMA Journal, 52, 478-483.

[12] Hilal, L., Shahait, M., Mukherji, D., Charafeddine, M., Farhat, Z. and Temraz, S. (2015) Prostate Cancer in the Arab World: A View from the Inside. Clinical Genitourinary Cancer, 13, 505-511. https://doi.org/10.1016/j.clgc.2015.05.010

[13] Heyns, C.F., Fisher, M., Lecuona, A. and van der Merwe, A. (2011) Prostate Cancer among Different Racial Groups in the Western Cape: Presenting Features and Management. South African Medical Journal, 101, 267-270. https://doi.org/10.7196/SAMJ.4420

[14] Niroomand, H., Nowroozi, M., Ayati, M., Jamshidian, H., Arbab, A. and Momeni, S.A. (2016) Relationship between Perineural Invasion in Prostate Needle Biopsy Specimens and Pathologic Staging after Radical Prostatectomy. Nephro-Urology Monthly, 8, e36022. https://doi.org/10.5812/numonthly.36022

[15] Amégbor, K., Yao Seddoh, T., Tengué, K., Songne-Gnamkoulamba, B., Napo-Koura, G. and James, K. (2009) Epidemiology and Histopronostic of Prostatic Cancer in Togo: About 202 Cases Diagnosed at the Laboratory of Pathology of the Tokoin Teaching Hospital of Lome. Progrès en Urologie, 19, 112-115. https://doi.org/10.1016/j.purol.2008.10.008

[16] Kabore, F.A., Zango, B., Sanou, A., Yameogo, C. and Kirakoya, B. (2011) Prostate Cancer Outcome in Burkina Faso. Infectious Agents and Cancer, 6, S6. https://doi.org/10.1186/1750-9378-6-S2-S6

[17] Delongchamps, N.B., Singh, A. and Haas, G.P. (2006) The Role of Prevalence in the Diagnosis of Prostate Cancer. Cancer Control, 13, 158-168. https://doi.org/10.1177/107327480601300302

[18] Luboldt, H.J., Schindler, J.F. and Rubben, H. (2007) Age-Specific Reference Ranges for Prostate-Specific Antigen as a Marker for Prostate Cancer. EAU-EBU Update 
Series, 5, 38-48. https://doi.org/10.1016/j.eeus.2006.10.003

[19] Yarney, J., Vanderpuye, V. and Mensah, J. (2013) Clinicopathologic Features and Determinants of Gleason Score of Prostate Cancer in Ghanaian Men. Urologic Oncology: Seminars and Original Investigations, 31, 325-330.

https://doi.org/10.1016/j.urolonc.2011.01.018

[20] Saadat, S.H., Barghoutha, I., Kazzazib, A., Momtahenb, S., Djavanb, B. and Chamssuddina, A. (2012) Risk Factors Associated with Perineural Invasion in Prostate Cancer. African Journal of Urology, 18, 82-86.

https://doi.org/10.1016/j.afju.2012.08.001

[21] Shih, W.J., Gross, K., Mitchell, B., Collins, J., Wierzbinski, B., Magoun, S., et al. (1992) Prostate Adenocarcinoma Using Gleason Scores Correlates with Prostate Specific Antigen and Prostate Acid Phosphatase Measurements. Journal of the National Medical Association, 84, 1049-1050.

[22] Vargas, S.O., Jiroutek, M., Welch, W.R., Nucci, M.R., D’Amico, A.V. and Renshaw, A.A. (1999) Perineural Invasion in Prostate Needle Biopsy Specimens Correlation with Extraprostatic Extension at Resection. American Journal of Clinical Pathology, 111, 223-228. https://doi.org/10.1093/ajcp/111.2.223

[23] Altuwaijri, S. (2012) Role of Prostate Specific Antigen (PSA) in Pathogenesis of Prostate Cancer. Journal of Cancer Therapy, 3, 331-336.

https://doi.org/10.4236/jct.2012.34043 